Canadian Science Publishing

Canadian Journal of Earth Sciences Revue canadienne des sciences de la Terre

Implementation of a rigorous least-squares modification of Stokes formula to compute a gravimetric geoid model over Saudi Arabia (SAGE013)

\begin{tabular}{|r|l|}
\hline Journal: & Canadian Journal of Earth Sciences \\
\hline Manuscript ID: & cjes-2014-0192.R2 \\
\hline Manuscript Type: & Article \\
\hline Date Submitted by the Author: & 06-May-2015 \\
\hline Complete List of Authors: & $\begin{array}{l}\text { Abdalla, Ahmed; Omdurman Islamic University, Surveying Engineering } \\
\text { Mogren, Saad; King Saud University }\end{array}$ \\
\hline Keyword: & $\begin{array}{l}\text { additive corrections, GOCE, GPS-levelling data, modification of Stokes } \\
\text { formula, SAGEO13 }\end{array}$ \\
\hline \multicolumn{2}{|l}{} \\
\hline
\end{tabular}

SCHOLARONE

Manuscripts 


\title{
Implementation of a rigorous least-squares modification of Stokes formula to compute a gravimetric geoid model over Saudi Arabia (SAGEO13)
}

\author{
Ahmed Abdalla ${ }^{1,2,3, *}$ and Saad Mogren ${ }^{4}$ \\ 1,* Department of Surveying Engineering, Faculty of Engineering Sciences, Omdurman \\ Islamic University, Omdurman, Sudan \\ ${ }^{2, *}$ Department of Surveying Engineering, Faculty of Engineering, University of \\ Khartoum, Khartoum, Sudan \\ 3,* Octantis Advanced Ltd., Geodetic Training Centre, Khartoum, Sudan \\ Email: ahmed.abdalla@live.se, ahmed.abdalla@uofk.edu \\ ${ }^{4}$ Geology and Geophysics Department, College of Sciences, King Saud University, \\ Riyadh, Saudi Arabia \\ Email: smogren@ksu.edu.sa
}




\section{Abstract}

A precise gravimetric geoid model (SAGEO13) is computed for the Kingdom of Saudi Arabia using a rigorous stochastic computational method. The computational methodology is based on a combination of least-squares (LS) modification of Stokes formula and the additive corrections for topographic, ellipsoidal, atmospheric and downward continuation effects on the geoid solution. In this study, we used the terrestrial gravity data, digital elevation model (SRTM3) and seven geopotential models (GGMs) to compute the a new geoid model for Saudi Arabia. The least-squares coefficients are derived based on the optimisation of the input modification parameters. The gravimetric solution and its additive corrections are computed based on the optimum LS coefficients. Comparing to GPS-levelling data, SAGEO13 shows a fit of $18 \mathrm{~cm}$ (RMS) after using the 4-parameter fitting model.

\section{Keywords:}

additive corrections, GOCE, GPS-levelling data, modification of Stokes formula, SAGEO13, SRTM3 


\section{Introduction}

Geoid is one of the most important surfaces in geodesy and it is defined as an Earth's equipotential surface that approximately converges with the mean sea level (MSL) and extends below the continents, except in some areas like the Netherlands and the Black Sea where the geoid is above the topography (cf Abdalla, 2009). The geoid surface is much smoother than the Earth surface, its undulations make it rougher than the surface of the ellipsoid of revolution which is recognized as the best approximation of the geoid. The geoid surface is complex and therefore it is not easy to define it by a simple mathematical model (cf. Abdalla, 2009; Abdalla and Fairhead, 2011; Abdalla and Tenzer, 2011).

The surface integral in the original Stokes formula (Stokes, 1849) is assumed to be applied over the whole Earth. But due to the fact that the global coverage of the terrestrial gravity data is very poor, it is not possible to fulfill this assumption. Meaning that the surface integral will be truncated to small cap $\sigma_{0}$ around the computation point, therefore, truncation errors stem as a consequence. To reduce these errors, the modification of Stokes formula based on the combination of terrestrial and satellite gravity data was introduced in two methods. The deterministic methods intend to decrease the effects of the remote zone resulting from the truncation of the original Stokes formula and therefore improving their convergence using lower-degree geopotential coefficients, among them Molodensky et al. (1962); Wong and Gore (1969); Meissl (1971); Vaníček and Kleusberg (1987). The stochastic methods aim to reduce the errors of the terrestrial gravity and spherical harmonic coefficients of GGM by combining both of them optimally in the leastsquares sense (see e.g. Sjöberg, 1981; Wenzel, 1982; Sjöberg, 1984, 2003c).

An early study for the geoid modelling in the Kingdom of Saudi Arabia (KSA) was conducted by Algarni (1997), he employed the GPS points and the orthometric heights to derive the geometrical geoid model using least-squares fitting model. Currently, there are two existing geometrical geoid models, the first one is the KSA geoid model by Ngiboglu (2008), it is derived from the GPS points co-located with the basic levelling network established by the Arabian-American Oil Company (ARAMCO). The variation in the density of the points distribution is noticeable in the western parts where the point measurements 
are rare opposite to the eastern parts which are highly-covered, particularly over the oil field areas.

The second geoid model is produced by the Saudi Ministry of Municipality and Rural (MOMRA) as described by Alrajhi et al. (2009). MOMRA model is combined with first order levelling network, high precision GPS measurements attached to the International Terrestrial Reference Frame (ITRF2000), and EGM08 (cf. Pavlis et al., 2012). The leastsquares collocation was utilised for fitting the model with the GPS-levelling data and EGM08 in an iterative way (cf. Alothman et al., 2011, 2012, 2013)

The main objective of this paper is to compute a precise gravimetric geoid of Saudi Arabia using heterogeneous data sets e.g the newly adjusted terrestrial gravity data, the existing GPS-levelling points, SRTM3 digital elevation model (DEM) and the recent global geopotential models (GGM) from GOCE mission. In this study, we apply the modified Stokes formula to combine all data by means of least-squares. This method is efficient and widely known as the "KTH method", it was developed at the Royal Institute of Technology (KTH) in Sweden (cf. Sjöberg, 1980, 1984, 1991, 2003a). The main difference between the KTH method and conventionally used approaches for the gravimetric geoid determination thus comes from a different treatments of the gravity corrections and consequently different types of gravity anomaly data used in the Stokes integral convolution. In the traditional Stokesian approaches, the observed gravity anomalies are first corrected for the topographic and atmospheric gravitational effects and subsequently reduced to the geoid surface. The integral convolution of the modified Stokes kernel with the corrected and reduced gravity anomalies provides the final gravimetric geoid after adding the primary indirect topographic effect on the geoid. In the KTH method, the Stokes integration is applied directly to the observed gravity anomaly data at the Earth's surface. The integral convolution of the modified Stokes kernel with the observed gravity anomalies provides the approximate geoid heights. The complete contribution of the direct and secondary indirect effects of topography and atmosphere on the gravity anomalies and consequently the primary indirect effects of topography and atmosphere on the geoid heights are treated as the combined topographic and atmospheric corrections applied to the approximate geoid 
heights (Sjöberg, 2003b). Similarly, the contribution of the downward continuation of the gravity anomalies from the Earth's surface onto the geoid surface is treated as the downward continuation correction to the approximate geoid heights (Abdalla, 2009; Abdalla and Tenzer, 2011; Abdalla and Fairhead, 2011; Abdalla, 2013a). The KTH method has been successfully implemented over different regions of the world e.g. in Sweden (Nahavandchi, 1998), Zambia (Nsombo, 1998), Baltic countries (Ellmann, 2001, 2004), Greece (Daras, 2008), Sudan (Abdalla, 2009; Abdalla and Fairhead, 2011), Kazakhstan (Inerbayeva, 2010), New Zealand (Abdalla and Tenzer, 2011). Moreover, this method shows excellent results in the mountainous areas as shown in the studies conducted over Ethiopia (Hunegnaw, 2001), Iran mountains (Kiamehr, 2006), over Mount Kilimanjaro in Tanzania(Ulotu, 2009) and over the area of Konya in central Turkey (Abbak et al., 2012). Therefore it makes us interested in using this method for the Saudi geoid.

This paper is divided into seven sections, the organization of these sections is as follows: Following to this introductory section is section 2 which addresses the input data sets in the study area (global geopotential models (GGMs), digital elevation model (DEM), terrestrial gravity data, and GPS-levelling points). Section 3 is devoted for the geoid determination, the computation method is presented and the numerical results and analysis are also shown. The additive corrections for the effects corresponding to topography, atmosphere, gravity downward continuation to the mean sea level, and ellipsoidal fitting are recapitulated in section 4 . The numerical results and the analysis of the new precise geoid model is presented section 5. The assessment of the obtained gravimetric model is found in section 6. Concluding remarks about the results and further discussions are addressed in the end of this paper in section 7 .

\section{Data sets}

\subsection{GGMs}

In this study, we utilise a number of GGMs models. The same GOCE models, namely, GOCO01S, GO-CONS-GCF-2-DIR-R1 (DIR1) and DIR2 (cf. Pail et al., 2010; Bruinsma 
et al., 2010; Pail et al., 2011) were previously over Saudi Arabia used in (cf. mogren, 2012). In addition, we also include GOCE fifth generation DIR5 (Brockmann et al., 2014) and TIM5 (Bruinsma et al., 2013). We also used well-known combined models, particularly EGM08 (Pavlis et al., 2012) and GL04C (Förste et al., 2006) models. The models are carefully tested and evaluated at each degree and order for the sake of obtaining a precise evaluation. For all models, the maximum degree is truncated at 224 so as to agree with the maximum degree and order of GOCO01S. The evaluation is conducted at an interval of 1 degree and order (Abdalla and Tenzer, 2012; Abdalla et al., 2012; Abdalla, 2013b). Figure 1a shows the comparison between the geoid heights derived from tested geopotential models and the geometrical geoid heights of the GPS-levelling data. GOCO01S, DIR5 and TIM5 have the minimum RMS among the tested models, therefore they are selected for the computation of the Saudi gravimetric geoid model in the current study. The GGMs are also used for testing the terrestrial gravity anomalies (cf. Figure 1b). EGM08 has good agreement with the terrestrial data at degree and order 360, therefore we use EGM08 for filling the empty blocks in the final grid.

[Figure 1 about here]

\subsection{DEM}

The digital elevation models represent the Earth topographic features in a digital format. The accuracy of the DEM is highly important in geoid computation due to the fact that errors in the DEM will be propagated into the geoid models when conducting the construction of the free-air gravity anomalies and later in the computation of topographic and downward continuation corrections. Most of DEMs are potential to contain errors based on their computation methodologies. In the current study, we used a DEM obtained from SRTM3 (Figure 2) .

The SRTM3 DEM is a 3 arc-second resolution model, which is not enclosed by a regional error information (cf. Holmes et al., 2000). This limitation makes no prior knowledge about the accuracy of the truncated regions on the DEM. Therefore to evaluate the DEM over the study area, we have to test it with one of the existing local data sets e.g. levelling 
points, aerial photos or local DEMs. Moreover, other directional derivatives of surface grid (slope, aspect, various orders of first and second vertical derivative) that are used for the analysis of the geometry if the DEM surface are likely to be contaminated by systematic errors stem from the data resolution or the methods that used to produce the DEM. More information about the estimation of the statistical parameters in terrain modelling can be found in Moore et al. (1991); Mitášová and Hofierka (1993).

[Figure 2 about here]

\subsection{Terrestrial gravity data}

The terrestrial gravity data of the Saudi Arabia were collected over decades yielding three fundamental gravity data sets in the Kingdom. The first one was conducted between 1973 and 1975 by the Arabian Geophysical and Surveying Company (ARGAS), it was initiated to cover the entire Kingdom (Mogren, 2004). The second gravity campaign was jointly carried out by Saudi Ministry of Petroleum and Mineral Resources (MPMR) and U.S Geological Survey (USGS). The surveys were conducted from 1974 to 1977, additional surveys were also done by USGS in 1980. The third gravity surveys were done over Cover Rocks and Empty Quarter areas by ARAMCO and were provided as relative gravity measurements to the National Plan for Science, Technology and Innovation (NPST) program, King Saud University (KSU), Project No. 09-SPA873-02(cf. Miller et al., 1989; Mogren et al., 2013). The gravity surveys were adjusted and connected to the new absolute gravity station at KSU before using in the geoid calculation, more details are found in Mogren et al. (2013). The input gravity data set for this study is consist of 459848 surface gravity points (cf. Figure 3).

[Figure 3 about here]

The validation of sparse gravity data was done using the cross-validation technique (leave one out) and the potential gravity data for the geoid determination were carefully refined as shown in (Abdalla, 2013b). The cross-validation method was introduced by Geisser 
and Eddy (1979) and it is an established technique for assessing the data. The Leaveone-out cross validation (LOOCV) is used in this study to predict new gravity values. A procedure for applying LOOCV has been addressed by Kiamehr (2007). In this study, 389

points were detected as outliers (cf. Figure 4) and removed from the data set according to the tolerance value of suspicious gross errors which was set to reject all error values larger than \pm 10 mGal (cf. Abdalla, 2013b).

[Figure 4 about here]

After the validation process of the sparse data, the evaluated data are gridded into $1 \times 1$ arc-min grid. For the interpolation, we used the function "Surface" in Generic Mapping Tool (GMT) software (Wessel and Smith, 1991) to create our grid as used in Claessens et al. (2009). The surface function using continuous curvature splines in tension. The tension factor of $\mathrm{T}=0.25$ is recommended for potential fields (see Smith and Wessel, 1990). The Free-air gravity anomalies are constructed from the gridded Bouguer data and the corresponding SRTM heights (cf. Ellmann, 2002), the outliers and empty blocks are replaced by EGM08 (Pavlis et al., 2012) as illustrated in (Figure 5).

[Figure 5 about here]

\subsection{GPS-levelling points}

The local vertical datum in Saudi Arabia stands on different tide gauges in east and west coasts, the main GPS-levelling network established by ARAMCO is based on two geodetic datums, namely, WGS84 and Saudi Vertical Datum 1978 (SAVD78). SAVD78 is connected with mean sea level at Jeddah tide gauge to the west coast in the Red Sea. On the other hand, the General Directorate Surveys (GDS) old vertical datum is known as SAVD71 and connected to Ain Al-Abd 1970 tide gauge near borders with Kuwait. The GDS GPS-levelling network is based on ITRF2000 and SAVD71 datums. It is worth mentioning that datum transformation is needed to keep both ARAMCO and GDS datums compatible (cf. Alothman et al., 2012, 2013). 
A number of 384 GPS-levelling points were provided by the general commission for survey (GCS) of Saudi Arabia to the National Plan for Science, Technology and Innovation (NPST) program of King Saud University, (Project No. 09-SPA873-02), in ITRF2000 coordinates Epoch 2004.0, the GPS-levelling data are mainly used as an external tool to validate the gravimetric geoid heights. The geometrical geoid heights derived from the GPS-levelling points are compared with the gravimetric heights to show the accuracy of the gravimetric solution. The GPS-levelling are similarly used to evaluate GGMs. In section 2.1, the GPS-levelling were used to select the best-fit GGM for this study. The assessment of the gravimetric heights is highly dependent to the GPS-levelling points. However, as shown in Figure ??, the distribution of the GPS-levelling points is not adequate to provide high accuracy agreement between the geometrical and gravimetric heights.

\section{Modified Stokes formula}

The gravimetric geoid height $N$ is computed as a sum of the following components (Sjöberg, 2003b):

$$
N=\tilde{N}+\delta N^{T}+\delta N^{A}+\delta N^{d w c}+\delta N^{e l l}
$$

where $\tilde{N}$ is the approximate geoid height, $\delta N^{T}$ the combined topographic correction, $\delta N^{A}$ the combined atmospheric correction, $\delta N^{d w c}$ the downward continuation correction and $\delta N^{e l l}$ the ellipsoidal correction for the formulation of the Stokes formula in the spherical approximation to the problem.

The approximate geoid height in Equation 3.1 is computed using the modified Stokes formula in the following form (Sjöberg, 2003c).

$$
\tilde{N}=\frac{\mathrm{R}}{4 \pi \gamma_{0}} \iint_{\sigma_{0}} S^{\bar{n}}(\psi) \Delta g \sin \psi d \sigma_{0}+\frac{\mathrm{R}}{2 \gamma_{0}} \sum_{n=2}^{\bar{n}} b_{n} \Delta g_{n}^{G G M}
$$

where $R$ denotes the Earth's mean radius, $\gamma_{0}$ denotes the normal gravity evaluated at the surface of the reference ellipsoid GRS80 (Moritz, 1980), $\psi$ is the geocentric angle, $S^{\bar{n}}(\psi)$ is the modified Stokes function, $\Delta g$ is the terrestrial gravimetric data and $d \sigma_{0}$ denotes 
the surface integration element and $b_{n}$ are the least-squares coefficients

The first term on the right-hand side of Equation 3.2 represents the terrestrial gravity anomaly contribution to the approximate geoid heights. This contribution is computed by the integral convolution of the observed gravity anomalies at the Earth's surface with the modified Stokes kernel $S^{\bar{n}}(\psi)$ can be defined as

$$
S^{\bar{n}}(\psi)=S(\psi)-\sum_{n=2}^{\bar{n}} \frac{2 n+1}{2} b_{n} P_{n}(\cos \psi)
$$

where $S(\psi)$ is the (original) Stokes kernel, $P_{n}(\cos \psi)$ are the Legendre polynomials of degree $n$ for the argument of cosine of the spherical distance $\psi$. The second constituent on the right-hand side of Equation 3.2 represents the GGM contribution to the approximate geoid heights. This contribution is computed from the GGM coefficients up to a maximum degree $\bar{n}$ of spherical harmonics and from a set of the least-squares modification parameters $\left\{b_{n}: n=2,3, \ldots, \bar{n}\right\}$. The Laplace spherical harmonics $\Delta g_{n}^{G G M}$ for the gravity anomalies of degree $n$ in Equation 3.2 are defined as (e.g., Heiskanen and Moritz, 1967, page 89)

$$
\Delta g_{n}^{G G M}=\frac{\mathrm{GM}}{a^{2}}\left(\frac{a}{r}\right)^{n+2}(n-1) \sum_{m=-n}^{n} c_{n, m} \mathrm{Y}_{n, m}
$$

where $c_{n, m}$ are the GGM coefficients of the disturbing potential $T$. The least-squares modification parameters $b_{n}$ are defined by the following linear system of observation equations (cf. Sjöberg, 2003c):

$$
\sum_{r=2}^{\bar{n}} b_{r} a_{k, r}=h_{k} \quad(k=2,3, \ldots, \bar{n})
$$

\section{Additive corrections}

\subsection{Topographic correction}

It was emphasized by Sjöberg (2009) that the topographic bias is successfully determined by the Boghuer shell alone. Therefore, the combined topographic correction in Equation 
3.1 is computed using the following simple expression (cf. Sjöberg, 2001):

$$
\delta N^{T} \approx-\frac{2 \pi}{\gamma_{0}} G \rho^{T} H^{2}
$$

where $\rho^{T}=2670 \mathrm{~kg} \mathrm{~m}^{-3}$ is the adopted value of the topographic density (Hinze, 2003), and the height of the computation point above sea level.

\subsection{Atmospheric correction}

The combined atmospheric correction in Equation 3.1 is defined as (cf. Sjöberg and Nahavandchi, 2000)

$$
\delta N^{A}=-\frac{2 \pi R}{\gamma_{0}} \rho_{0}^{A} \sum_{n=2}^{\bar{n}}\left(\frac{2}{n-1}-b_{n}-Q_{n}^{\bar{n}}\right) H_{n}-\frac{2 \pi R}{\gamma_{0}} \rho_{0}^{A} \sum_{n=\bar{n}+1}^{\infty}\left(\frac{2}{n-1}-\frac{n+2}{2 n+1} Q_{n}^{\bar{n}}\right) H_{n}
$$

where $\rho_{0}^{A}$ is the adopted nominal value of the atmospheric density at sea level, that is, $\rho_{o}^{A}=1.230 \mathrm{~kg} \mathrm{~m}^{-3}$ (cf Sjöberg, 2001). The surface (topographic) height functions of degree $n$ in Equation 4.2 read

$$
H_{n}=\sum_{m=-n}^{n} H_{n, m} Y_{n, m}
$$

where $H_{n, m}$ are the numerical coefficients of the global elevation model (GEM) of degree $n$ and order $m$.

\subsection{Downward continuation correction}

The downward continuation correction $\delta N^{d w c}$ in Equation 3.1 consists of three terms that are computed individually (cf. Ågren, 2004):

$$
\delta N^{d w c}=\delta N^{d w c, 1}+\delta N^{L 1, F a r}+\delta N^{d w c, L 2}
$$


The first term $\delta N^{d w c, 1}$ in Equation 4.4 is defined as (Sjöberg, 2003b)

$$
\delta N^{d w c, 1}=\frac{\Delta g}{\gamma_{0}} H+3 \frac{\tilde{\varsigma}}{r} H-\left.\frac{1}{2 \gamma_{0}} \frac{\partial \Delta g}{\partial r}\right|_{r=R+H} H^{2}
$$

where $\tilde{\varsigma}$ denotes the approximate value of the height anomaly at the computation point. Due to the diminutive value of $\delta N^{d w c, 1}=1 \mathrm{~mm}$ that corresponds to an error of about $1 \mathrm{~m}$ for the height of the computation point of $H=2000 \mathrm{~m}, \tilde{\varsigma}$ is obtained by Equation 3.2 (Sjöberg, 2003d). The linear vertical gravity anomaly gradient $\frac{\partial \Delta g}{\partial r} \mid$ at the computation point is calculated according to the expression for the analytical continuation given in Heiskanen and Moritz (1967). It reads

$$
\left.\frac{\partial \Delta g}{\partial r}\right|_{r=R+H}=\frac{R^{2}}{2 \pi} \iint_{\sigma_{0}} \frac{\Delta \mathrm{g}_{P}-\Delta \mathrm{g}}{\ell_{0}^{3}} d \sigma_{0}-\frac{2}{R} \Delta g_{P}
$$

where $\Delta g$ and $\Delta g_{p}$ are the values of the surface gravity anomaly at the positions of the computation and running integration points, respectively.

The Euclidean spatial distance $\ell_{0}^{3}(\psi)$ in Equation 4.6 reads

$$
\ell_{0}^{3}(\psi)=2 R \sin \frac{\psi}{2}
$$

The downward continuation correction terms $\delta N^{L 1, F a r}$ and $\delta N^{d w c, L 2}$ in Equation 4.4 are computed using the following expressions

$$
\begin{aligned}
\delta N^{L 1, F a r} & =\frac{R}{2 \gamma_{0}} \sum_{n=2}^{\bar{n}}\left(b_{n}+Q_{n}^{\bar{n}}\right)\left[\left(\frac{R}{\mathrm{r}}\right)^{n+2}-1\right] \Delta g_{n}^{G G M} \\
\delta N^{d w c, L 2} & =\left.\frac{R}{4 \pi \gamma} \iint_{\sigma_{0}} S^{\bar{n}}(\psi) \frac{\partial \Delta g}{\partial r}\right|_{r=R+H}\left[H_{P}-H_{Q}\right] d \sigma_{0}
\end{aligned}
$$

where $H_{P}$ and $H_{Q}$ are the topographical heights at the positions of the computation and running integration points, respectively. 


\subsection{Ellipsoidal correction}

The numerical investigations by Sjöberg (2004) showed that the ellipsoidal effect can reach several decimetres for an integration cap size $\left(\psi=10^{\circ}\right)$ in Stokes' formula. The ellipsoidal correction $\delta N^{e l l}$ in Equation 3.1 is computed approximately as (cf. Sjöberg, 2004)

$$
\delta N^{e l l}=\psi_{0}\left[\left(0.12-0.38 \sin ^{2} \theta\right) \Delta g+0.17 \tilde{N} \cos ^{2} \theta\right]
$$

where $\tilde{N}$ denotes the approximate geoid heights in meters and $\theta$ is the geocentric spherical latitude of the computation point.

\section{$5 \quad$ Numerical results}

\section{Optimisation of $\sigma^{2}, n$ and $\psi_{0}$}

Since we do not have any information about the accuracy of the terrestrial gravity data, we utilised a variance component estimation (VCE) procedure demonstrated by Tenzer (2008) to estimate the accuracy of the current gravity data. The VCE procedure uses the spherical radial basis functions (cf. Kusche and Klees, 2002; Koch and Kusche, 2002; Kusche, 2003) for the parameterisation of the gravity field to estimate the accuracy value of the local gravity. In particular, we employed Poisson kernel to obtain the accuracy of the gravity based on finding the optimal depth that corresponds to the minimum variance of the residuals. It is well seen from Figure 6 that the $3.5 \mathrm{~km}$ is the optimal depth that corresponds to the minimum variance $\left(7 \mathrm{mGal}^{2}\right)$. When going further above, the inversion of the Poisson kernel becomes singular for the depths less than $3.5 \mathrm{~km}$. It starts to give instable results with large and unpredictable numbers (cf. Abdalla and Tenzer, 2014).

[Figure 6 is about here]

For the selection of GGM that best fits our area of study, we consider testing the GGMs performance with GPS-levelling (Figure ??) before and after using the 4-parameter model (cf. Kotsakis and Sideris, 1999). The comparison in Table 1 shows that among all models 
DIR5, TIM5 and GOCO01S preserve their good agreement with GPS-levelling before and after the fitting process. Therefore, we confine all subsequent computations and analysis to these models.

[Table 1 is about here]

To select the optimal modification degree $n$ and the spherical cap $\psi$, first we investigate the performance of the GGMs with respect to the GPS-levelling data (cf. Figure ??). We notice from Figure 1a that GOCO01S, DIR5 and TIM5 data among all GGMs are best-fit to the GPS-levelling data. We select two potential points at $n=138 n=195$ and (see red circles) where the GGMs have the best agreement with the GPS-levelling data, we additionally included $n=224$. We considered a number of choices for the spherical cap e.g. $\psi=0.5^{\circ}, 1^{\circ}, 1.5^{\circ}, 2^{\circ}, 2.5^{\circ} 3^{\circ}, n=138,195$ and $224, \sigma^{2}=7 \mathrm{mGal}^{2}$, the obtained results of these choices are illustrated in Table 2

[Table 2 is about here]

Table 3 shows further statistical details for DIR5, TIM5 and GOCO01S models. It appears that DIR5 and TIM5 almost have an identical performance with GPS-levelling data when the modification degree $n=224$ and the spherical cap radius $\left(\psi=1^{\circ}\right)$ before and after using fitting. GOCO01S has a comparable RMS before fitting at $n=195$ and $\left(\psi=1.5^{\circ}\right)$, the fitting model have a limited improvement $(\sim 7 \mathrm{~cm})$.

[Table 3 is about here]

Based on the results obtained in Table 3, we compute final solution of SAGEO13 based on DIR5 model. The approximate geoid and additive corrections are produced (see Figure 7), the final geoid model is illustrated in Figure 8.

[Figure 7 about here]

\section{Geoid assessment}

In this section, the gravimetric geoid model (cf. Figure 8) will be validated against the GPS-levelling data. The validation is conducted by comparing the differences between https://mc06.manuscriptcentral.com/cjes-pubs 
the geometric and the gravimetric heights. Since the geoid is computed from heterogeneous data sets, it is likely to suffer from errors which propagate from these data sets and potentially contaminate the gravimetric solution. A one-by-one magnitude of the additive corrections on the geoid accuracy is shown and hence the geoid estimators are presented in different versions. First, without additive corrections and then each correction is subsequently added to the approximate gravimetric solution. The additive corrections are computed over the GPS-levelling points and the comparison has been made as shown in Table 4. One may say that the topography correction doesn't rely on the LS parameters.

[Figure 8 about here]

The GPS-levelling data are used to evaluate the accuracy (RMS) of the gravimetric solution obtained in this study. The RMS of the differences between the GPS-levelling data and the approximate gravimetric solutions in Table ?? reaches about $0.27 \mathrm{~m}$ and the residuals mean value is obtained at $0.08 \mathrm{~m}$. The atmospheric correction is obtained in a mm level, it does not have any impact on the final accuracy of the geoid solution at this stage. The impact of removing the topographic effects gives comparable results and reduces the discrepancies in the gravimetric estimators while the RMS has an increase of $2 \mathrm{~cm}$. The contribution of the downward continuation correction to the geoid estimator is significant, it reduces RMS of the differences to $1 \mathrm{~cm}$ in the final solution. The effect of the downward continuation when involving with the topographic correction is clearly tangible in the gravimetric solution in terms of RMS. The combination of the downward continuation and the topographic correction improves STD and increases the mean value of the differences from $0.08 \mathrm{~m}$ (approximate geoid) to $0.14 \mathrm{~m}$ which affects RMS by increasing $2 \mathrm{~cm}$. The ellipsoidal and atmospheric corrections have been added to the combination of the downward continuation and topographic corrections to find whether they will contribute to the accuracy of the estimator or not. They remain insignificant when they individually added to the estimators (cf. Table 4). It is worth mentioning that the additive corrections have not added any changes in the final RMS after applying the fitting procedure, RMS remains at $0.18 \mathrm{~m}$ as seen in Table 4.

[Table 4 about here]

https://mc06.manuscriptcentral.com/cjes-pubs 
Since the mean value of the differences between the geometrical and gravimetric solutions contains biases, it means that the systematic errors are still existing (see Table 4). The elimination of the outliers is commonly used to remove points with large biases (with big and low biases). To overcome the impact these sources of errors employ 4-parameter model (cf. Kotsakis and Sideris, 1999) to remove the errors.

The observation equations were adapted to the residuals of the differences between the geometric and gravimetric geoid heights $\Delta N$ at the GPS-levelling testing network and solved using the least-squares analysis. The model is given as

$$
\mathbf{a}_{\mathbf{i}} \mathbf{x}=\left[\begin{array}{c}
\cos \phi_{i} \cos \lambda_{i} \\
\cos \phi_{i} \sin \lambda_{i} \\
\sin \phi_{i} \\
1
\end{array}\right] \times\left[\begin{array}{c}
x_{1} \\
x_{2} \\
x_{3} \\
x_{4}
\end{array}\right]
$$

where $\left(\phi_{i}, \lambda_{i}\right)$ are the geodetic latitude and longitude of the GPS-levelling point, the vector $\mathrm{x}$ contains the four unknown parameters $x_{1} \rightarrow x_{4}$

The matrix system of observation is solved as

$$
\mathrm{Ax}=\Delta \mathrm{N}-\varepsilon
$$

where $\mathbf{A}$ is an $n \times m$ matrix of the coefficientsx is the vector of unknown parameters, $\Delta \mathbf{N}$ denotes the vector of the differences between the geometrical and gravimetric geoid heights and $\varepsilon$ is the residuals vector

applying least-square approach the parameters $\hat{\mathbf{x}}$ are obtained by

$$
\hat{\mathbf{x}}=\left(\mathbf{A}^{\mathrm{T}} \mathbf{A}\right)^{-1} \mathbf{A}^{\mathrm{T}} \Delta \mathbf{N}
$$

and from Ulotu (2009, equation 7.10, page 151) we have

$$
\hat{\varepsilon}=\left(\mathbf{I}-\mathbf{A}\left(\mathbf{A}^{\mathrm{T}} \mathbf{A}\right)^{-1} \mathbf{A}^{\mathrm{T}}\right) \Delta \mathbf{N}
$$


where I denotes the identity matrix

Table 5 demonstrates that SAGEO13 is showing a good consistency with the GPS-levelling data in terms of the mean value of the differences. The RMS of SAGEO13 is significantly smaller than the RMS of DIR-R5 and EGM08 before the fitting where it reaches about $0.60 \mathrm{~m}$. The statistics of the residuals before and after using the fitting model. The 4-parameter model has reduced the RMS of SAGEO13 from $0.29 \mathrm{~m}$ to $0.18 \mathrm{~m}$. On the other hand, a large improvement in the RMS of EGM08 and GOCO01S is obtained after the fitting due to the high discrepancies between the data (see Table 5).

[Table 5 about here]

Tables ?? emphasizes that SAGEO13 performs better than the geopotential models. It appears that LSMS has reduced the truncation errors and the noise of the GGMs, the contribution of LSMS has improved the final RMS by about $50 \%$, it also improves the consistency with the GPS-levelling to be around $0.15 \mathrm{~cm}$ instead of 0.50 .

\section{Summary and concluding remarks}

We computed a gravimetric geoid model (SAGEO13) using the optimum LS modification of Stokes formula. We used a Free-air anomaly grid constructed from the terrestrial gravity measurements and EGM08. The geopotential models GOCO01S, GO-CONSGCF-2-DIR-R1 and DIR-R2 and the recent DIR5 and TIM5 from GOCE, and EIGENGL04C and EGM08 combined models were evaluated to select the best model that fits with the GPS-levelling data. GOCO01S and GOCE fifth generation models (DIR5 and TIM5) have shown high agreement with the GPS-levelling data. DIR5 and TIM5 were more compatible with LSMS

SAGEO13 was computed using compatible LS parameters, the combination of the modified Stokes kernel and the GGM provided the gravimetric geoid estimator (approximate geoid). The additive corrections were also computed and individually added to measure their impact on the gravimetric solution. The systematic errors were removed using

https://mc06.manuscriptcentral.com/cjes-pubs 
4-parameter model which has improved the RMS of the differences between the geometric and gravimetric geoid heights from $0.29 \mathrm{~m}$ to $0.18 \mathrm{~m}$ for the LSMS solution based on GOCE DIR5, modification degree $n=224$ and spherical cap radius $\psi=1^{\circ}$. The additive corrections have had small values over the GPS-levelling points before fitting, however they do not change RMS after fitting. The implementation of LSMS has reduced the noise of the GGM, SAGEO13 has shown a good performance with respect to GPS-levelling comparing to the GGMs before and after applying 4-parameter model.

The distribution and quality of the GPS-levelling data in Figure 3 are insufficient to properly evaluate the accuracy of the geoid model in Saudi Arabia. Hence, the density of the GPS-levelling data needs to be improved by conducting more GPS-levelling measurements to increase the dense of the existing data.

\section{Acknowledgments}

We are grateful for the Associate Editor Dr. Randolph Enkin for his careful handling of this manuscript. Two anonyomous reviewers are cordially acknowledged for their thoughtful criticism, constructive comments and helpful suggestions on the first manuscript of this paper, which considerably improved the paper. This Project was funded by the National Plan for Science, Technology and Innovation (MAARIFAH), King Abdulaziz City for Science and Technology, Kingdom of Saudi Arabia, Award Number (09-SPA873-02).

\section{References}

Abbak, R.A., Sjöberg, L.E., Ellmann, A., Ustun, A., 2012. A precise gravimetric geoid model in a mountainous area with scarce gravity data: a case study in central turkey. Studia Geophysica et Geodaetica 56, 909-927.

Abdalla, A., 2009. Determination of a gravimetric geoid model of Sudan using the KTH method. Master's thesis. Royal Institute of Technology (KTH).

Abdalla, A., 2013a. The Combined Modelling of the Regional Quasigeoid of New Zealand Using Gravity and GPS-levelling Data. Ph.D. thesis. University of Otago.

Abdalla, A., 2013b. Towards a precise gravimetric geoid model in the saudi arabia (sageo13). geoid calculation technical report funded by dr. saad mogren, principle investigator of project no. 09-spa873-02, quasi-geoid model for saudi arabia: Application for levelling with gps, the national plan for science, technology and innovation (npst) program, king saud university. 
Abdalla, A., Fairhead, D., 2011. A new gravimetric geoid model for sudan using the KTH method. Journal of African Earth Sciences 60, 213-221.

Abdalla, A., Fashir, H., Ali, A., Fairhead, D., 2012. Validation of recent GOCE/GRACE geopotential models over Khartoum State - Sudan. Journal of Geodetic Science 2, 88-97.

Abdalla, A., Tenzer, R., 2011. The evaluation of the New Zealand's geoid model using the KTH method. Geodesy and Cartography 37, 5-14.

Abdalla, A., Tenzer, R., 2012. The global geopotential and regional gravimetric geoid/quasigeoid models testing using the newly adjusted levelling dataset for new zealand. Applied Geomatics .

Abdalla, A., Tenzer, R., 2014. The integral-equation-based approaches for modelling the local gravity field in the remove-restore scheme, in: Rizos, C., Willis, P. (Eds.), Earth on the Edge: Science for a Sustainable Planet. Springer Berlin Heidelberg. number 139 in International Association of Geodesy Symposia, pp. 283-289.

Ågren, J., 2004. Regional Geoid Determination Methods for the Era of Satellite Gravimetry : Numerical Investigations Using Synthetic Earth Gravity Models. dissertation.

Algarni, D.A., 1997. Geoid modeling in saudi arabia. ITC Journal 2, 114-120.

Alothman, A., Gruber, T., Bouman, J., 2011. Analysis of gravimetric and gps/levelling derived geoids for saudi arabia, in: Presented at the 2011 General Assembly of the European Geosciences Union, pp. April 3-8, 2011.

Alothman, A., Gruber, T., Bouman, J., 2012. Evaluation of height system biases for regional levelling network in saudi arabia using egm08 and goce models, in: Presented at the 2012 General Assembly of the European Geosciences Union.

Alothman, A., Gruber, T., Bouman, J., 2013. Evaluation of height system biases for regional levelling network in saudi arabia using EGM08 and GOCE models, p. 1126.

Alrajhi, M., Yanar, R., Hawarey, M., Alomar, A., 2009. Evaluation of height system biases for regional levelling network in saudi arabia using egm08 and goce models, in: Presented at the 2009 General Assembly of the European Geosciences Union.

Brockmann, J.M., Zehentner, N., Höck, E., Pail, R., Loth, I., Mayer-Gürr, T., Schuh, W.D., 2014. EGM_tim_r105: An independent geoid with centimeter accuracy purely based on the GOCE mission. Geophysical Research Letters 41, 8089-8099.

Bruinsma, S., Marty, J.C., Balmino, G., Biancale, R., Förste, C., Abrikosov, O., Neumayer, H., 2010. GOCE Gravity Field Recovery by Means of the Direct Numerical Method.

Bruinsma, S.L., Förste, C., Abrikosov, O., Marty, J.C., Rio, M.H., Mulet, S., Bonvalot, S., 2013. The new ESA satellite-only gravity field model via the direct approach. Geophysical Research Letters 40, 3607-3612. 
Claessens, S., Hirt, C., Featherstone, W., Kirby, J.F., 2009. Computation of a new gravimetric quasigeoid model for New Zealand. Technical report prepared for Land Information New Zealand by Western Australia Centre for Geodesy. Technical Report. Curtin University of Technology. Perth, Australia.

Daras, I., 2008. Determination of a gravimetric geoid model of Greece using the method of KTH. Master's thesis. Royal Institute of Technology (KTH).

Ellmann, A., 2001. Least squares modification of Stokes formula with application to the Estonian geoid. Licentiate thesis.

Ellmann, A., 2002. An improved gravity anomaly grid and a geoid model for estonia, in: Proceedings of the Estonian Academy of Sciences. Geology, Estonian Academy Publishers, Tallin, Estonia. pp. 199-214.

Ellmann, A., 2004. The geoid for the Baltic countries determined by the least squares modification of Stokes' formula. dissertation.

Förste, C., Flechtner, F., Schmidt, R., König, R., Meyer, U., Stubenvoll, R., Rothacher, M., Barthelmes, F., Neumayer, H., Biancale, R., Bruinsma, S., Lemoine, J., Loyer, S., 2006. A mean global gravity field model from the combination of satellite mission and altimetry/gravimetry surface data: EIGEN-GL04C. Geophysical Research Abstracts 8.

Geisser, S., Eddy, W.F., 1979. A predictive approach to model selection. Journal of the American Statistical Association 74, 153.

Heiskanen, W., Moritz, H., 1967. Physical Geodesy. Series of books in geology, W. H. Freeman, San Francisco.

Hinze, W., 2003. Bouguer reduction density, why 2.67? Geophysics 68, 1559.

Holmes, K.W., Chadwick, O.A., Kyriakidis, P.C., 2000. Error in a USGS 30-meter digital elevation model and its impact on terrain modeling. Journal of Hydrology 233, $154-173$.

Hunegnaw, A., 2001. Geoid determination over Ethiopia with emphasis on downward continuation of gravity anomailes. Doctoral dissertation. Royal Institute of Technology (KTH). Stockholm, Sweden. Geoid determination over Ethiopia with emphasis on downward continuation of gravity anomailes.

Inerbayeva, D., 2010. Determination of a gravimetric geoid model of Kazakhstan using the KTH-method.

Kiamehr, R., 2006. Hybrid precise gravimetric geoid model for iran based on recent GRACE and SRTM data and the least squares modification of stokes formula. J. Physics of Earth and Space 32, 7-23.

Kiamehr, R., 2007. Qualification and refinement of the gravity database based on cross-validation approach - a case study of iran. Acta Geodaetica Et Geophysica Hungarica 42, 285-295. 336AX Times Cited:1 Cited References Count:18. 
Koch, K., Kusche, J., 2002. Regularization of geopotential determination from satellite data by variance components. Journal of Geodesy 76, 259-268.

Kotsakis, C., Sideris, M.G., 1999. On the adjustment of combined GPS/levelling/geoid networks. Journal of Geodesy 73, 412-421.

Kusche, J., 2003. A Monte-Carlo technique for weight estimation in satellite geodesy. Journal of Geodesy 76, 641-652.

Kusche, J., Klees, R., 2002. Regularization of gravity field estimation from satellite gravity gradients. Journal of Geodesy 76, 359-368. 584DP Times Cited:17 Cited References Count:38.

Meissl, P., 1971. Preparations for the Numerical Evaluation of Second Order Molodensky-type Formulas. Ohio State University, Research Foundation.

Miller, C., Showail, A., Kane, M., Khoja, I., Alghamdi, S., 1989. A Gravity survey of parts of quadrangles 26E, 26F, 27E, and 27F, northeastern Arabian Shield. Technical Report USGSOF-09-3. Ministry of Petroleum and Mineral Resources, Directorate General of Mineral Resources. Jeddah, Saudi Arabia.

Mitášová, H., Hofierka, J., 1993. Interpolation by regularized spline with tension: II. application to terrain modeling and surface geometry analysis. Mathematical Geology $25,657-669$.

Mogren, S., 2004. Geophysical Investigations on the Najd Fault System. Ph.D. thesis. University of Newcastle upon Tyne. England, UK. EThOS Persistent ID: uk.bl.ethos.489840,.

mogren, S., 2012. Results of testing gps/leveling data against the global geo-potential models (ggms) as initial step for quasi-geoid model for saudi arabia, in: Presented at the AGU Fall Meeting, San Francico, USA. pp. December 3-7, 2012.

Mogren, S., Hassan, E., Al-Zahrani, A.S., Almotairi, E.M., Almuslmani, B., Abdalla, A., Blitzkow, D., Fairhead, D., Almutery, R.S., Malek, M.M., AlZahrani, H., Al-Bogmi, T., El-Shehri, M., 2013. Quasi-geoid model for saudi arabia: application for levelling with gps. technical report. project no. 09-spa873-02, supported financially by the national plan for science, technology and innovation (npst) program, king saud university. (under reviewing process).

Molodensky, M., Eremeev, V., Yurkina, M., 1962. Methods for study of the external gravitational field and figure of the earth. Jerusalem, Israel Program for Scientific Translations, 1962; [available from the Office of Technical Services, U.S. Dept. of Commerce, Washington] -1 .

Moore, I.D., Grayson, R.B., Ladson, A.R., 1991. Digital terrain modelling: A review of hydrological, geomorphological, and biological applications. Hydrological Processes 5, $3-30$.

Moritz, H., 1980. Advanced physical geodesy. Wichmann ; Tunbridge, Eng., Abacus Press, Karlsruhe. 
Nahavandchi, H., 1998. Precise gravimetric-GPS geoid determination with improved topographic corrections applied over Sweden. dissertation. Precise gravimetric-GPS geoid determination with improved topographic corrections applied over Sweden.

Ngiboglu, S.M., 2008. Final report on the determination of the geoid for the Kingdom of Saudi Arabia. Internal Document NASA/TP-1998-206861. General Directorate of Military Survey, GDMS. Riyadh, Saudi Arabia.

Nsombo, P., 1998. Preliminary geoid over zambia. Journal of Geodesy 72, 144-153. Zd724 Times Cited:1 Cited References Count:32.

Pail, R., Bruinsma, S., Migliaccio, F., Förste, C., Goiginger, H., Schuh, W.D., E. Hoeck, M.R., Brockmann, J., Abrikosov, O., Veicherts, M., Fecher, T., R. Mayrhofer, I.K., Sansò, F., Tscherning, C., 2011. First goce gravity field models derived by three different approaches .

Pail, R., Goiginger, H., Schuh, W., Höck, E., Brockmann, J.M., Fecher, T., Gruber, T., Mayer-Gürr, T., Kusche, J., Jäggi, A., Rieser, D., 2010. Combined satellite gravity field model GOCO01S derived from GOCE and GRACE. Geophysical Research Letters $37,5 \mathrm{PP}$.

Pavlis, N.K., Holmes, S.A., Kenyon, S.C., Factor, J.K., 2012. The development and evaluation of the earth gravitational model 2008 (EGM2008). Journal of Geophysical Research 117, B04406.

Sjöberg, L.E., 1980. Least squares combination of satellite harmonics and integral formulas in physical geodesy. Gerlands Beitraege zur Geophysik 89, 371-377.

Sjöberg, L.E., 1981. Least squares combination of satellite and terrestrial data in physical geodesy. Annales de Geophysique 37, 25-30.

Sjöberg, L.E., 1984. Least squares modification of Stokes' and Vening Meinesz' formulas by accounting for errors of truncation, potential coefficients and gravity data. University of Uppsala, Institute of Geophysics, Dept. of Geodesy.

Sjöberg, L.E., 1991. Refined least-squares modification of stokes formula. Manuscripta Geodaetica 16, 367-375.

Sjöberg, L.E., 2001. Topographic and atmospheric corrections of gravimetric geoid determination with special emphasis on the effects of harmonics of degrees zero and one. Journal of Geodesy 75, 283-290.

Sjöberg, L.E., 2003a. A computational scheme to model the geoid by the modified stokes formula without gravity reductions. Journal of Geodesy 77, 423-432.

Sjöberg, L.E., 2003b. A computational scheme to model the geoid by the modified stokes formula without gravity reductions. Journal of Geodesy 77, 423-432.

Sjöberg, L.E., 2003c. A general model for modifying stokes formula and its least-squares solution. Journal of Geodesy 77, 459-464.

Sjöberg, L.E., 2003d. A solution to the downward continuation effect on the geoid determined by stokes' formula. Journal of Geodesy 77, 94-100. 
Sjöberg, L.E., 2004. A spherical harmonic representation of the ellipsoidal correction to the modified stokes formula. Journal of Geodesy 78, 180-186. 865VZ Times Cited:3 Cited References Count:12.

Sjöberg, L.E., 2009. The terrain correction in gravimetric geoid computation-is it needed? Geophysical J. Int. 176, 14-18.

Sjöberg, L.E., Nahavandchi, H., 2000. The atmospheric geoid effects in stokes formula. Geophysical Journal International 140, 95-100.

Smith, W.H.F., Wessel, P., 1990. Gridding with continuous curvature splines in tension. Geophysics 55, 293-305.

Stokes, G., 1849. On the variation of gravity and the surface of the earth. Trans. Cambridge Phil. Soc. 8, 672.

Tenzer, R., 2008. On the accuracy assessment of input gravity data in local gravity field modeling. Contributions to Geophysics and Geodesy 38, 133-149.

Ulotu, P.E., 2009. Geoid model of Tanzania from sparse and varying gravity data density by the KTH method. Doctoral dissertation. Royal Institute of Technology (KTH). Stockholm, Sweden.

Vaníček, P., Kleusberg, A., 1987. The canadian geoid-stokesian approach. Manuscripta Geodaetica 12, 86-98.

Wenzel, H., 1982. Geoid computation by least-squares spectral combination using integral kernels, Internation, Tokyo, Japan. pp. 438-453.

Wessel, P., Smith, W.H.F., 1991. Free software helps map and display data. AGU 72.

Wong, L., Gore, R., 1969. Accuracy of geoid heights from modified stokes kernels. Geophysical Journal of the Royal Astronomical Society 18, 81-91. 


\section{Figures captions}

Figure 1: RMS of differences between geoid heights derived from GGMs and GPSlevelling data (1a) and evaluation between GGM-based gravity and terrestrial gravity data $(1 b)$

Figure 2: The digital elevation model of the Kingdom of Saudi Arabia

Figure 3: Distribution of the GPS-levelling (blue) and terrestrial gravity (red) points over the Kingdom

Figure 4: The outliers after applying LOOCV

Figure 5: The final $1 \times 1$ arc-min Free-air gravity anomaly grid constructed from local gravity data, EGM08 and SRTM3 elevation model . Unit: $1 \mathrm{mGal}$

Figure 6: Parameterisation of terrestrial gravity data for variance estimation using depth minimisation criterion

Figure 7a: Modified Stokes solution

Figure 7b: DIR5 contribution at degree 224

Figure 7c: Ellipsoidal correction

Figure 7d: Atmospheric correction

Figure 7e: Topographic correction

Figure 7f: Downward continuation correction

Figure 7: Approximate geoid height, and additive corrections over Kingdom of Saudi Arabia

Figure 8: The gravimetric geoid model of Saudi Arabia (SAGEO13). Units: m 


\section{Tables captions}

Table 1: Statistics of the residuals of the GGM-based solutions before (BF) and after (AF) applying 4-parameter model. Units: $1 \mathrm{~m}$

Table 2: RMS of the differences between GPS-levelling data and different LSMS solutions based on different geopotential models (DIR5, TIM5 and GOCO01S) and different spherical cap radii. Units: $1 \mathrm{~m}$

Table 3:Statistics of the differences between the top LSMS solutions and the GPSlevelling before (BF) and after (AF) applying 4-parameter model. Units: $1 \mathrm{~m}$

Table 4: Statistics of differences between the geoid estimators $\tilde{N}$ based on LS modification parameters and GPS-levelling data. The impact of the additive corrections on the estimators accuracies is shown one-by-one for each correction. Units: $1 \mathrm{~m}$

Table 5: Statistics of the differences of SAGEO13, EGM08 and DIR5 versus GPSlevelling before $(\mathrm{BF})$ and after $(\mathrm{AF})$ applying 4-parameter model. Units: $1 \mathrm{~m}$ 


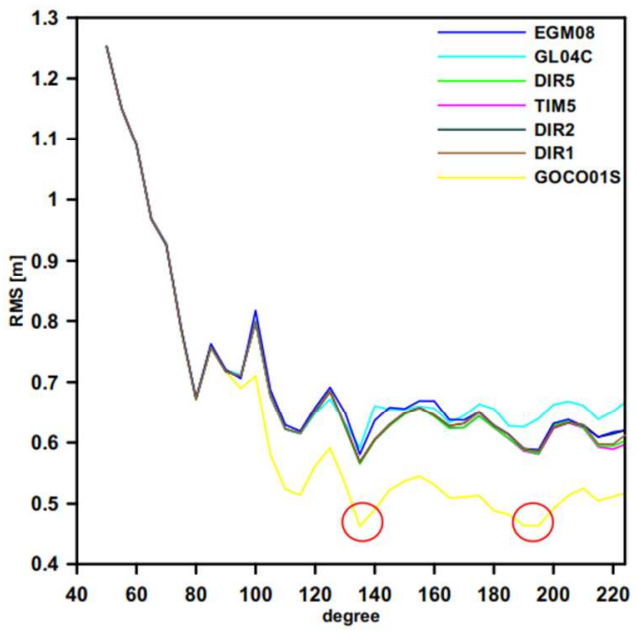

(a)

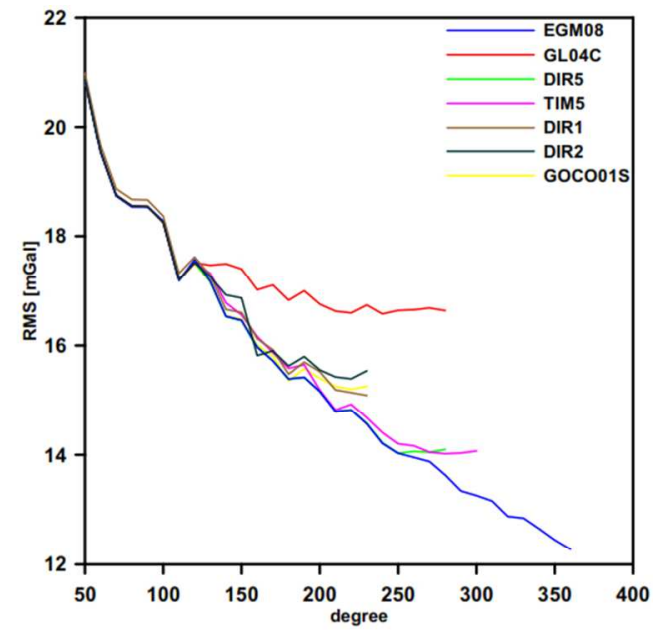

(b) 
Page $33^{\circ}$ of $36^{\circ}$ canadian $42^{\circ} 45^{\circ} 48^{\circ} 51^{\circ} \quad 54^{\circ} 57^{\circ}$

$33^{\circ}$

$30^{\circ}$

$27^{\circ}$

$24^{\circ}$

$21^{\circ}$

$12^{\circ}$

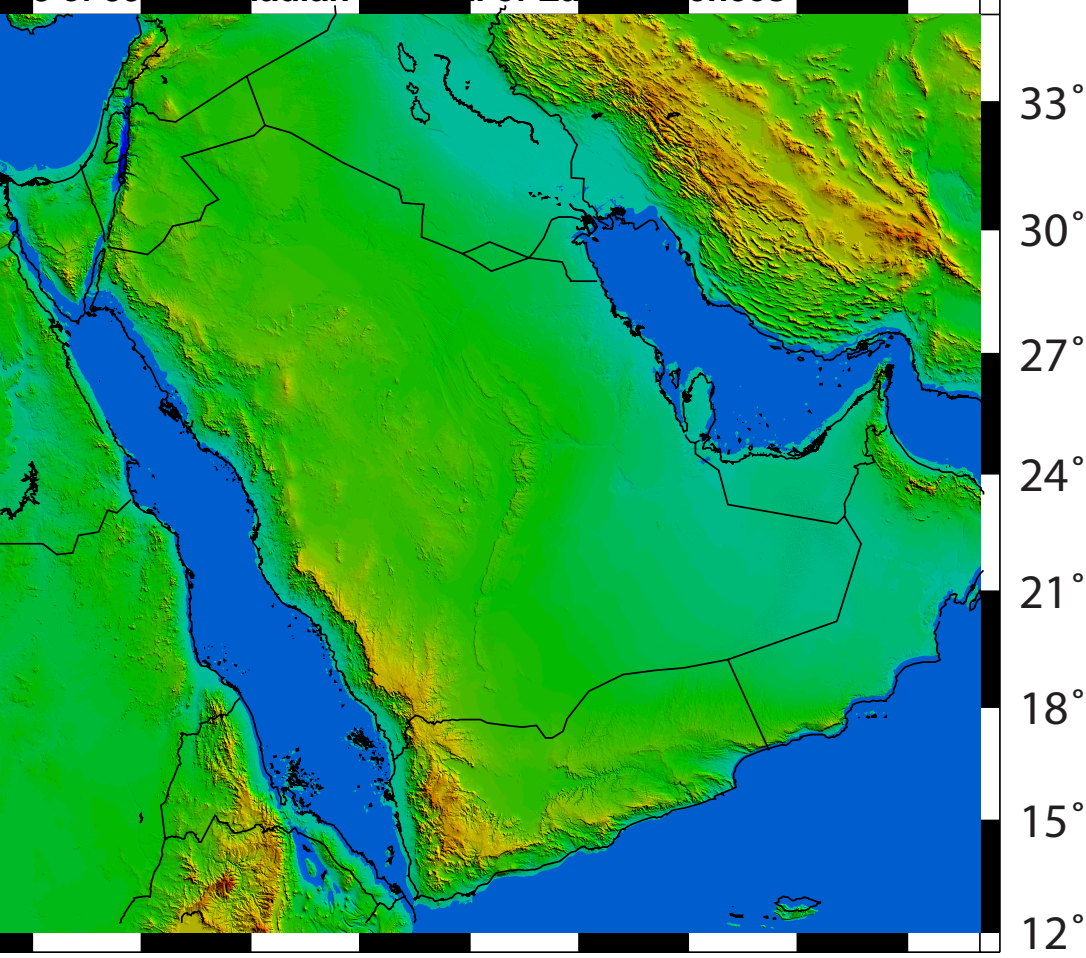

$33^{\circ} 36^{\circ} 39^{\circ} 42^{\circ} 45^{\circ} 48^{\circ} 51^{\circ} 54^{\circ} 57^{\circ}$ https://mc06.manuscriptcentral.com/cjes-pubs

[m]

$\begin{array}{llllll}0 & 900 & 1800 & 2700 & 3600 & 4500\end{array}$ 


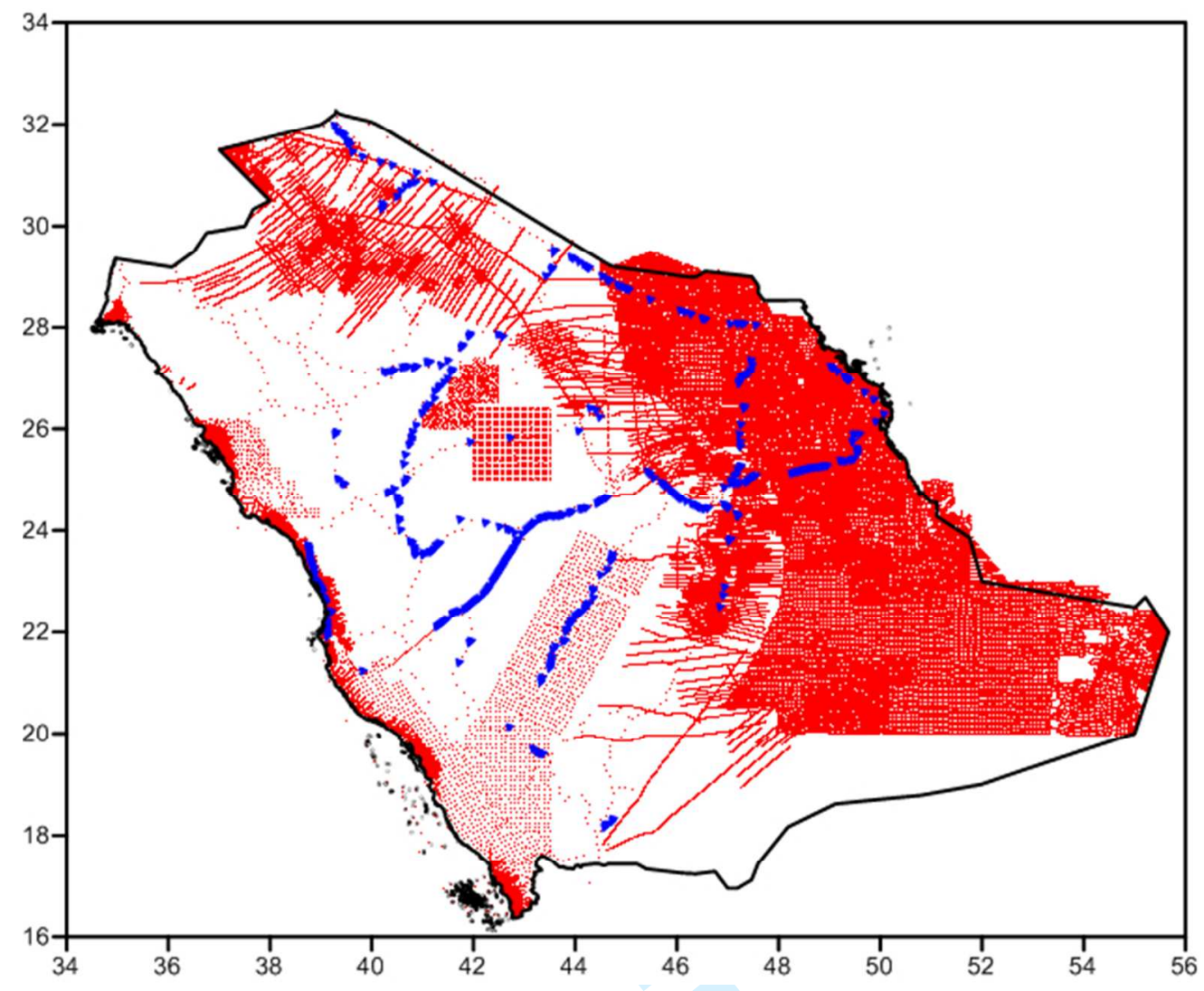


$30^{\circ}$

$36^{\circ} \quad 42^{\circ}$ $48^{\circ}$

$54^{\circ}$

$36^{\circ}$ Canadian Journal of Earth Sciences

$60^{\circ}$

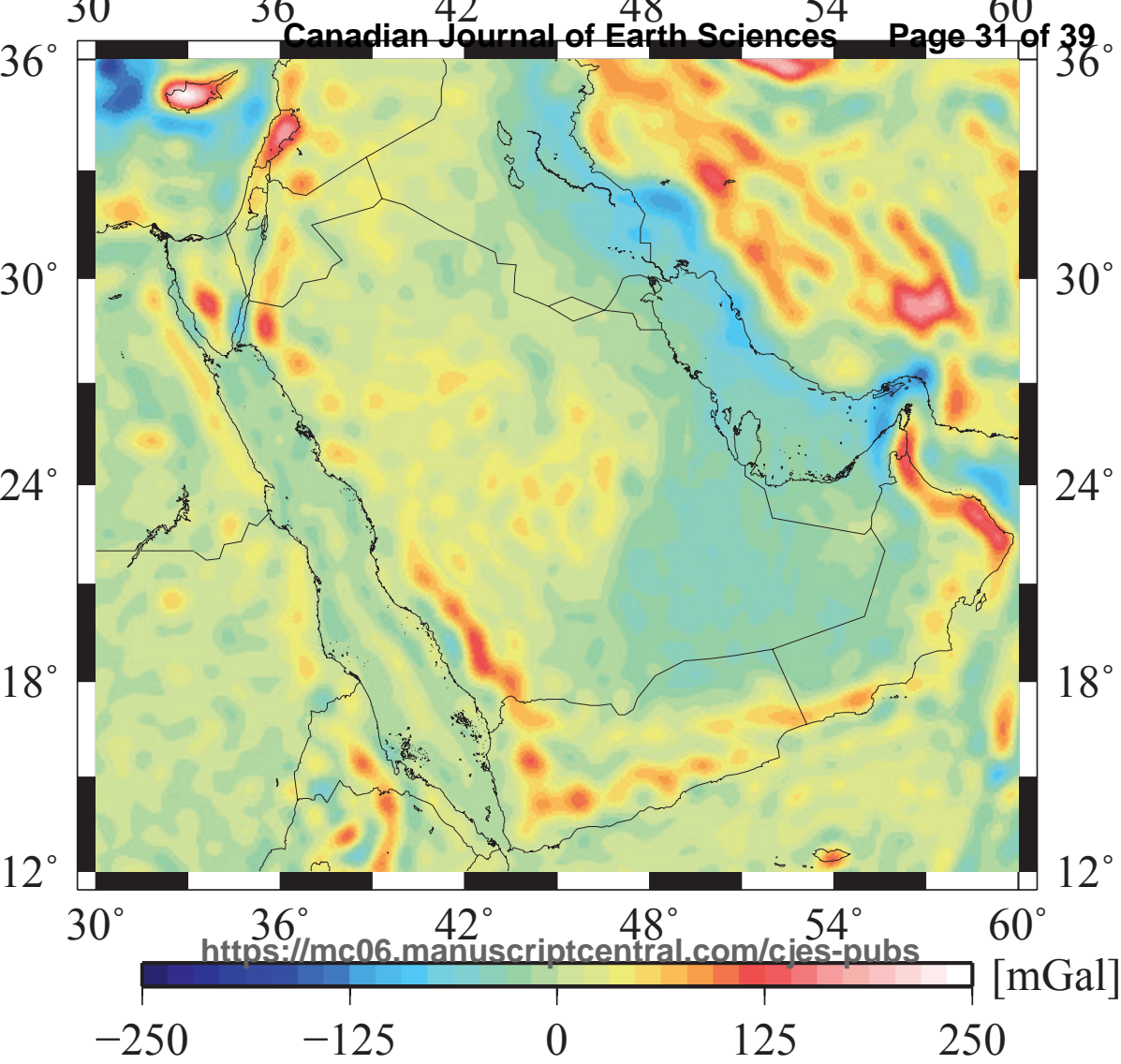




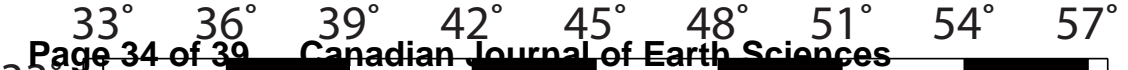

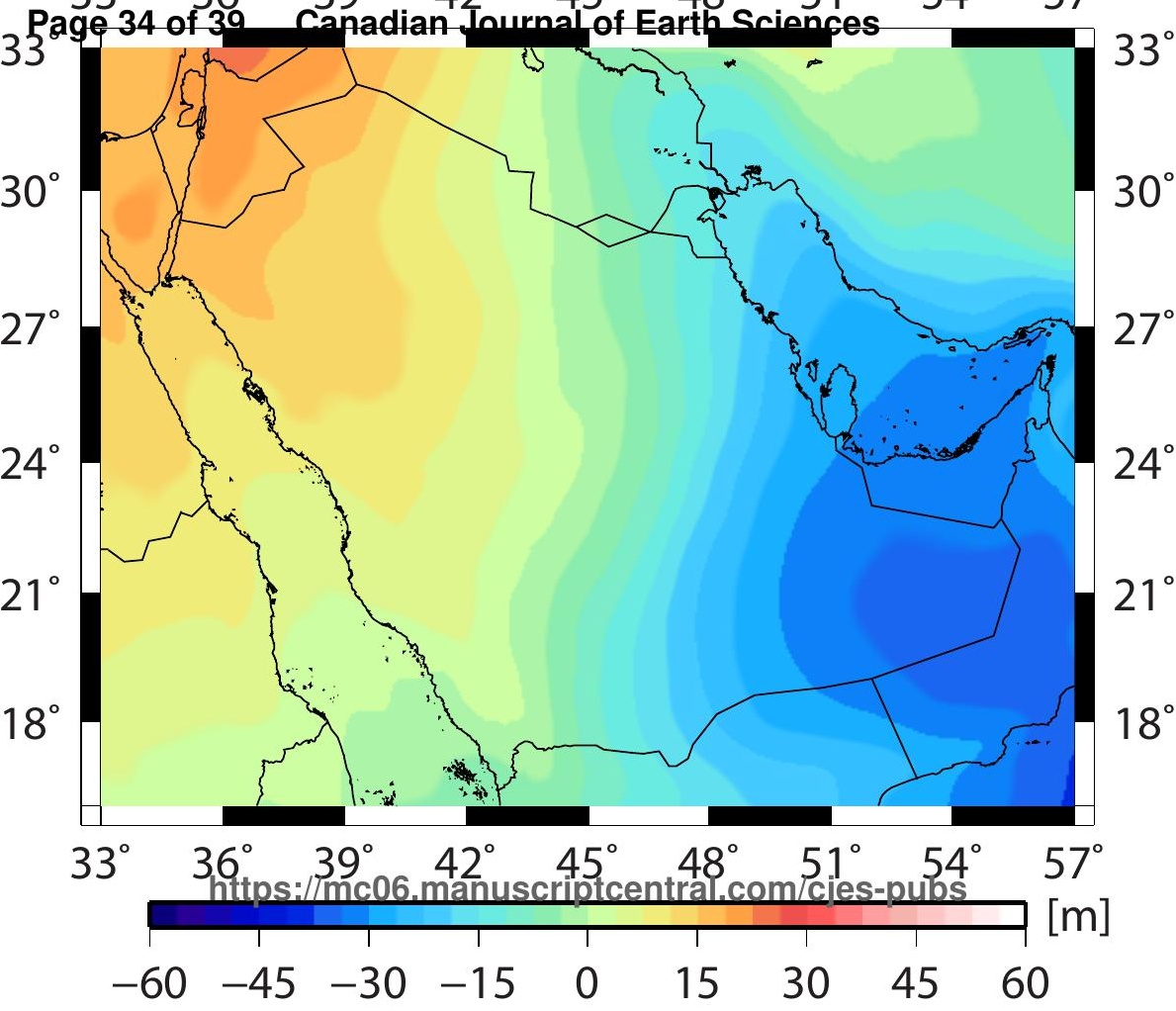


Table 1: Statistics of the residuals of the GGM-based solutions before (BF) and after (AF) applying 4-parameter model. Units: $1 \mathrm{~m}$

\begin{tabular}{cccccccccc}
\hline \multicolumn{1}{c}{ EGM08 } & \multicolumn{1}{c}{ GL04C } & \multicolumn{3}{c}{ DIR5 } & \multicolumn{2}{c}{ TIM5 } \\
\hline \multirow{2}{*}{$n$} & \multicolumn{1}{c}{ RMS } & [m] & & \\
\cline { 2 - 10 } & $\mathbf{B F}$ & AF & BF & AF & BF & AF & BF & AF \\
\hline $\mathbf{1 3 8}$ & 0.58 & 0.27 & 0.59 & 0.34 & 0.57 & $\mathbf{0 . 2 6}$ & 0.57 & $\mathbf{0 . 2 6}$ \\
$\mathbf{1 9 5}$ & 0.59 & 0.28 & 0.64 & 0.38 & 0.59 & $\mathbf{0 . 2 3}$ & 0.59 & $\mathbf{0 . 2 3}$ \\
$\mathbf{2 2 4}$ & 0.59 & 0.27 & 0.64 & 0.36 & 0.60 & $\mathbf{0 . 2 0}$ & 0.60 & $\mathbf{0 . 2 1}$ \\
\hline \multicolumn{4}{c}{ DIR1 } & \multicolumn{1}{c}{ DIR2 } & GOCO01S & & \\
\hline $\mathbf{1 3 8}$ & 0.59 & 0.27 & 0.57 & 0.27 & 0.45 & $\mathbf{0 . 2 6}$ & & \\
$\mathbf{1 9 5}$ & 0.58 & 0.25 & 0.58 & 0.24 & 0.46 & $\mathbf{0 . 2 3}$ & & \\
$\mathbf{2 2 4}$ & 0.60 & 0.24 & 0.61 & 0.24 & 0.52 & $\mathbf{0 . 2 4}$ & & \\
\hline
\end{tabular}


Table 2: RMS of the differences between GPS-levelling data and different LSMS solutions based on different geopotential models (DIR5, TIM5 and GOCO01S) and different spherical cap radii. Units: $1 \mathrm{~m}$

\begin{tabular}{|c|c|c|c|c|c|c|c|}
\hline & \multirow{3}{*}{ LSMS/Model } & \multicolumn{6}{|c|}{$\psi^{\circ}$} \\
\hline & & 0.5 & 1.0 & 1.5 & 2.0 & 2.5 & 3.0 \\
\hline & & \multicolumn{6}{|c|}{ RMS $[\mathbf{M}]$} \\
\hline \multirow{3}{*}{138} & DIR5 & 0.39 & 0.47 & 0.43 & 0.33 & 0.41 & 0.41 \\
\hline & TIM5 & 0.39 & 0.47 & 0.44 & 0.33 & 0.40 & 0.41 \\
\hline & GOCO01S & 0.39 & 0.47 & 0.39 & 0.33 & 0.39 & 0.32 \\
\hline \multirow{3}{*}{195} & DIR5 & 0.37 & 0.37 & 0.38 & 0.33 & 0.32 & 0.32 \\
\hline & TIM5 & 0.37 & 0.37 & 0.33 & 0.33 & 0.32 & 0.31 \\
\hline & GOCO01S & 0.39 & 0.38 & 0.31 & 0.33 & 0.35 & 0.32 \\
\hline \multirow{3}{*}{224} & DIR5 & 0.35 & 0.29 & 0.33 & 0.33 & 0.40 & 0.40 \\
\hline & TIM5 & 0.36 & 0.29 & 0.32 & 0.33 & 0.31 & 0.34 \\
\hline & GOCO01S & 0.37 & 0.36 & 0.32 & 0.33 & 0.35 & 0.32 \\
\hline
\end{tabular}


Table 3: Statistics of the differences between the top LSMS solutions and the GPS-levelling before (BF) and after (AF) applying 4-parameter model. Units: $1 \mathrm{~m}$

\begin{tabular}{|c|c|c|c|c|c|c|}
\hline & \multicolumn{2}{|c|}{ DIR5 (224), $\psi=1^{\circ}$} & \multicolumn{2}{|c|}{ TIM5 (224), $\psi=1^{\circ}$} & \multicolumn{2}{|c|}{$\operatorname{GOCO}(195), \psi=1.5^{\circ}$} \\
\hline & $\mathbf{B F}$ & $\mathbf{A F}$ & $\mathbf{B F}$ & $\mathbf{A F}$ & BF & $\mathbf{A F}$ \\
\hline Min & -0.53 & -0.53 & -0.56 & -0.54 & -0.73 & -0.73 \\
\hline Max & 0.74 & 0.45 & 0.74 & 0.47 & 0.71 & 0.61 \\
\hline Mean & 0.15 & 0.00 & 0.14 & 0.00 & 0.11 & 0.00 \\
\hline STD & 0.24 & 0.18 & 0.25 & 0.18 & 0.29 & 0.23 \\
\hline RMS & 0.29 & 0.18 & 0.29 & 0.18 & 0.30 & 0.23 \\
\hline
\end{tabular}


Table 4: Statistics of differences between the geoid estimators $\tilde{\mathrm{N}}$ based on LS modification parameters and GPS-levelling data. The impact of the additive corrections on the estimators accuracies is shown one-by-one for each correction. Units: $1 \mathrm{~m}$

\begin{tabular}{lccccccccc}
\hline \multirow{2}{*}{ Geoid estimator } & \multicolumn{1}{c}{ BF } & \multicolumn{4}{c}{ AF } \\
\cline { 2 - 9 } & Min & Max & Mean & STD & RMS & Min & Max & RMS \\
\cline { 2 - 9 }$\tilde{N}$ & -0.63 & 0.74 & 0.08 & 0.25 & 0.27 & -0.59 & 0.47 & 0.18 \\
$\tilde{N}+\delta N^{A}$ & -0.63 & 0.73 & 0.08 & 0.25 & 0.27 & -0.59 & 0.47 & 0.18 \\
$\tilde{N}+\delta N^{d w c}$ & -0.61 & 0.73 & 0.08 & 0.25 & 0.26 & -0.56 & 0.46 & 0.18 \\
$\tilde{N}+\delta N^{e l l}$ & -0.63 & 0.74 & 0.08 & 0.25 & 0.27 & -0.59 & 0.47 & 0.18 \\
$\tilde{N}+\delta N^{T}$ & -0.53 & 0.75 & 0.15 & 0.25 & 0.29 & -0.55 & 0.46 & 0.18 \\
$\tilde{N}+\delta N^{d w c}+\delta N^{T}$ & -0.52 & 0.74 & 0.14 & 0.24 & 0.28 & -0.53 & 0.45 & 0.18 \\
$\tilde{N}+\delta N^{d w c}+\delta N^{T}+\delta N^{A}$ & -0.53 & 0.74 & 0.15 & 0.24 & 0.29 & -0.53 & 0.45 & 0.18 \\
$\tilde{N}+\delta N^{d w c}+\delta N^{T}+\delta N^{A}+\delta N^{e l l}$ & -0.53 & 0.74 & 0.15 & 0.24 & 0.29 & -0.52 & 0.45 & 0.18 \\
\hline
\end{tabular}


Table 5: Statistics of the differences of SAGEO13, EGM08 and DIR5 versus GPS-levelling before (BF) and after (AF) applying 4-parameter model. Units: $1 \mathrm{~m}$

\begin{tabular}{ccccccc}
\hline & \multicolumn{2}{c}{ SAGEO13 } & \multicolumn{2}{c}{ EGMO8 } & \multicolumn{2}{c}{ DIR5 } \\
\cline { 2 - 7 } & BF & AF & \multicolumn{1}{c}{ BF } & AF & BF & AF \\
\hline Min & -0.53 & -0.53 & -0.42 & -0.68 & -0.29 & -0.70 \\
Max & 0.74 & 0.45 & 1.32 & 0.99 & 1.33 & 0.57 \\
Mean & 0.15 & 0.00 & 0.46 & 0.00 & 0.52 & 0.00 \\
STD & 0.24 & 0.18 & 0.32 & 0.25 & 0.27 & 0.20 \\
RMS & 0.29 & $\mathbf{0 . 1 8}$ & 0.57 & 0.25 & 0.60 & $\mathbf{0 . 2 0}$ \\
\hline
\end{tabular}

